\title{
SR-A ligand and M-CSF dynamically regulate SR-A expression and function in primary macrophages via p38 MAPK activation
}

\author{
Dejan Nikolic ${ }^{1}$, Lindsay Calderon², Liqin $\mathrm{Du}^{3}$ and Steven R Post ${ }^{1 *}$
}

\begin{abstract}
Background: Inflammation is characterized by dynamic changes in the expression of cytokines, such as M-CSF, and modifications of lipids and proteins that result in the formation of ligands for Class A Scavenger Receptors (SRA). These changes are associated with altered SR-A expression in macrophages; however, the intracellular signal pathways involved and the extent to which SR-A ligands regulate SR-A expression are not well defined. To address these questions, SR-A expression and function were examined in resident mouse peritoneal macrophages incubated with M-CSF or the selective SR-A ligand acetylated-LDL (AcLDL).

Results: M-CSF increased SR-A expression and function, and required the specific activation of p38 MAPK, but not ERK1/2 or JNK. Increased SR-A expression and function returned to basal levels 72 hours after removing M-CSF. We next determined whether prolonged incubation of macrophages with SR-A ligand alters SR-A expression. In contrast to most receptors, which are down-regulated by chronic exposure to ligand, SR-A expression was reversibly increased by incubating macrophages with AcLDL. AcLDL activated p38 in wild-type macrophages but not in SR-A-/- macrophages, and p38 activation was specifically required for ACLDL-induced SR-A expression.

Conclusions: These results demonstrate that in resident macrophages SR-A expression and function can be dynamically regulated by changes in the macrophage microenvironment that are typical of inflammatory processes. In particular, our results indicate a previously unrecognized role for ligand binding to SR-A in upregulating SR-A expression and activating P38 MAPK. In this way, SR-A may modulate inflammatory responses by enhancing macrophage uptake of modified protein/lipid, bacteria, and cell debris; and by regulating the production of inflammatory cytokines, growth factors, and proteolytic enzymes.
\end{abstract}

\section{Background}

SR-A is a multifunctional macrophage receptor that is upregulated during monocyte differentiation into macrophages, and is further increased in pathological conditions such as diabetes [1-3]. SR-A is also highly expressed by macrophages in atherosclerotic lesions and Alzheimer's plaques [4-6]. In contrast, decreased SR-A expression is associated with increased susceptibility to bacterial infection, progression of prostate cancer, and enhanced cytokine production [7-9]. Such results suggest important and complex roles for SR-A in modulating immune function and inflammation.

\footnotetext{
* Correspondence: spost@uams.edu

'Department of Pathology, University of Arkansas for Medical Sciences, Little Rock, Arkansas, 72205 USA

Full list of author information is available at the end of the article
}

Macrophage differentiation and recruitment during inflammation is mediated by changes in the local environment and the secretion of cytokines/chemokines such as M-CSF. M-CSF, which is produced by many cell types, is a cytokine that plays an essential role in monocyte-macrophage functions including membrane ruffling, cell migration, and the production of inflammatory mediators [reviewed in $[10,11]]$. Because of its role in the development of monocyte/macrophage cells, M-CSF is thought to play important roles in immune function and inflammatory diseases [reviewed in [12]]. For example, M-CSF is thought to promote atherosclerosis by increasing macrophage viability/differentiation, low-density lipoprotein (LDL) receptor-mediated lipoprotein uptake, and the expression of macrophage SR-A [12-14]. SR-A promotes foam cell formation by binding and
C Biomed Central

() 2011 Nikolic et al; licensee BioMed Central Ltd. This is an Open Access article distributed under the terms of the Creative Commons Attribution License (http://creativecommons.org/licenses/by/2.0), which permits unrestricted use, distribution, and reproduction in any medium, provided the original work is properly cited. 
internalizing modified lipoproteins [e.g., acetylated LDL (AcLDL), oxidized LDL (oxLDL)], but not native lipoproteins [15]. SR-A has also been associated with additional macrophage functions including cell adhesion to modified extracellular matrix, phagocytosis/clearance of apoptotic cells, and the modulation of macrophage activation and cytokine production [16-20]. Thus, increased SR-A expression may play an important part in the effects of M-CSF on immune function and inflammation. Taken further, the ability to inhibit M-CSF-induced SR-A expression may have important therapeutic implications. However, the cellular pathways that couple MCSF binding to increased SR-A expression are not known.

In addition to increased secretion of M-CSF, local inflammation results in the modification of proteins, alterations in the extracellular matrix (ECM), and tissue damage. Such modifications result in the formation and accumulation of SR-A ligands. Many receptors including receptor-tyrosine kinases (e.g., insulin receptors), G protein-coupled receptors (e.g., $\beta$-adrenergic receptors), and nutrient receptors (e.g., LDL receptors) are down-regulated by prolonged exposure to ligand. This negative feedback is mediated by activation of intracellular signaling pathways that regulate receptor expression. Although it might be of particular importance in diverse inflammatory conditions, the effect of modulating the concentration of SR-A ligand in tissue on SR-A expression in resident macrophages is not known.

SR-A gene expression is under the control of a proximal promoter in combination with an upstream enhancer element $[2,21,22]$. Binding of the transcription factor AP-1 to this upstream enhancer element has been shown to be sufficient to direct specific macrophage SRA expression [1,22]. Activation of AP-1 in inflammatory cells is primarily regulated by the mitogen activated protein kinases (MAPK), in particular via c-Jun phosphorylation by JNK and ATF2 phosphorylation by p38 MAPK [23]. Roles for both of these MAPKs in regulating SR-A expression in elicited macrophages has been suggested [24,25].

It has been suggested that different agents used to elicit resident peritoneal macrophages can alter macrophage populations, their regulation by intracellular signals, and macrophage responses e.g., superoxide production, chemokine generation, and Ab-dependent cellmediated cytolysis [26,27]. In this study, we used isolated resident peritoneal macrophages to examine the intracellular signaling pathways involved in regulating SR-A expression and function. We also examined whether chronic exposure to SR-A ligand alters SR-A expression in macrophages. Our results demonstrate that cytokine and SR-A ligand reversibly enhance SR-A expression and function via activation of p38 MAPK and the subsequent induction of SR-A transcription.

\section{Methods \\ Chemicals}

Dulbecco's modified Eagle's medium (DMEM) supplemented with L-glutamine, DMEM with 25 mM HEPES, and heat-inactivated fetal bovine serum (FBS) were purchased from GibcoBRL (Grand Island, NY). Penicillin and streptomycin, fucoidan, and actinomycin D were purchased from Sigma (St Louis, MO). Recombinant murine M-CSF and goat anti-mouse SR-A antibody were purchased from R\&D Systems (Minneapolis, MN). Rabbit anti-phospho-p44/42 (ERK1/2), anti-phosphop38, anti-phospho-SAPK/JNK, and anti-p38 MAPK antibodies were purchased from Cell Signaling Technology, Inc. (Beverly, MA). Anti-p44/42 (ERK1/2) and antiJNK1 antibodies were purchased from Santa Cruz Biotechnology, Inc (Santa Cruz, CA). The specific MAPK inhibitors SB203580 (p38), SP600125 (JNK1/2), and PD98059 (MEK) were purchased from EMD Biosciences, Inc (La Jolla, CA). Alexa ${ }^{488}$-Acetylated LDL was purchased from Molecular Probes, Inc (Eugene, OR) and Alexa ${ }^{647}$-conjugated 2F8 mAb from Serotec.

\section{Cell culture and treatment}

Resident (non-elicited) mouse peritoneal macrophages (MPMs) were harvested by peritoneal lavage with icecold sterile saline from male NIH Swiss mice (Harlan; Indianapolis, IN), and from $\mathrm{C} 57 \mathrm{Bl} / 6$ and $\mathrm{SR}-\mathrm{A}-/-$ mice on a $\mathrm{C} 57 \mathrm{Bl} / 6$ background (Figures $1 \mathrm{C}$ and $4 \mathrm{~B}$; Jackson Laboratory, Bar Harbor, ME). Animal care and use for all procedures were done according to protocols reviewed and approved by the Institutional Animal Care and Use Committee at University of Arkansas for Medical Sciences and the University of Kentucky. Isolated macrophages were cultured as previously described [28]. Briefly, peritoneal exudates were incubated overnight at $37^{\circ} \mathrm{C}$ and non-adherent cells removed by gently washing with PBS. Adherent macrophages were maintained in DMEM containing antibiotics and FBS (10\%) for $48 \mathrm{hrs}$ prior to use in experiments. MPMs were then treated with agonists in the presence or absence of specific inhibitors as described in figure legends. Following treatment, MPMs were washed with ice-cold PBS and cell lysates prepared by incubating cells in MBST/OG buffer (25 mM MES; $150 \mathrm{mM} \mathrm{NaCl} ; 60 \mathrm{mM}$ octylglucopyranoside; $1 \%$ Triton $\mathrm{X}-100 ; \mathrm{pH} 6.4$ ) containing protease and phosphatase inhibitors (Sigma, St. Louis, MO) for $45 \mathrm{~min}$ on ice. Cell lysates were centrifuged at 13,000 rpm for 15 min and the pellets were discarded. Protein concentration of supernatant was determined using the BioRad DC assay using BSA as a standard (Hercules, CA). 
A
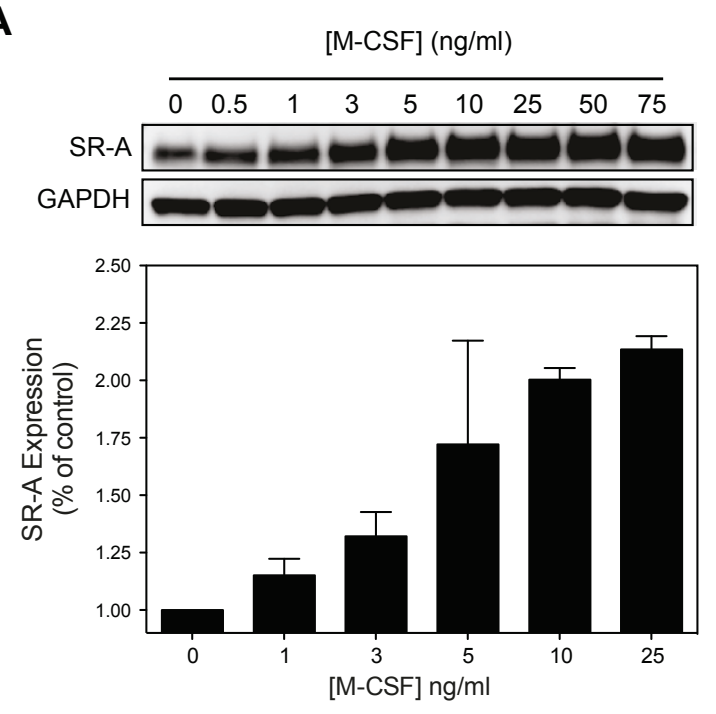

B
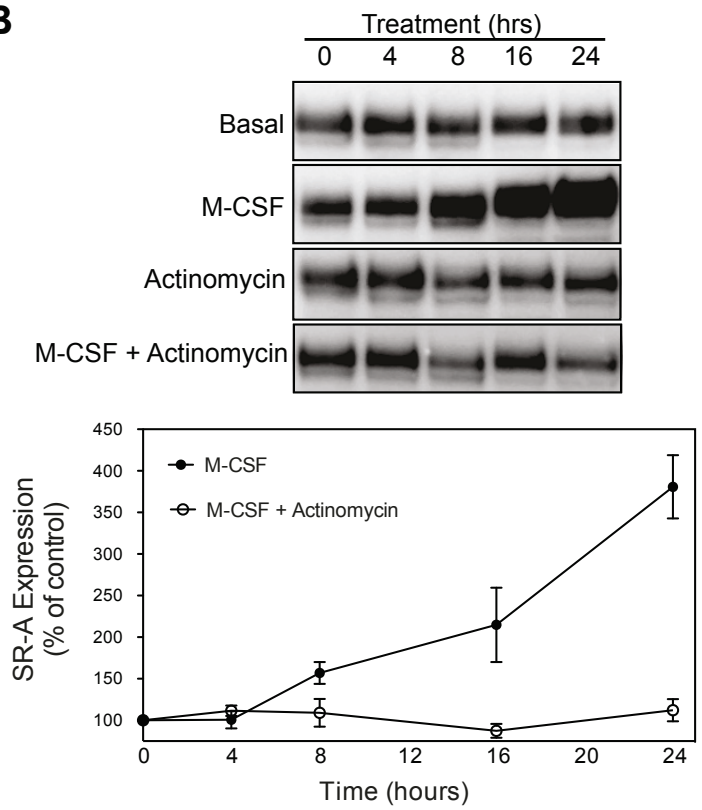

C

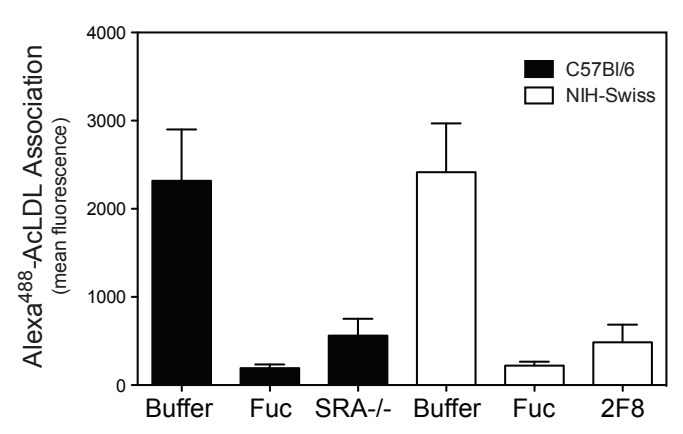

D

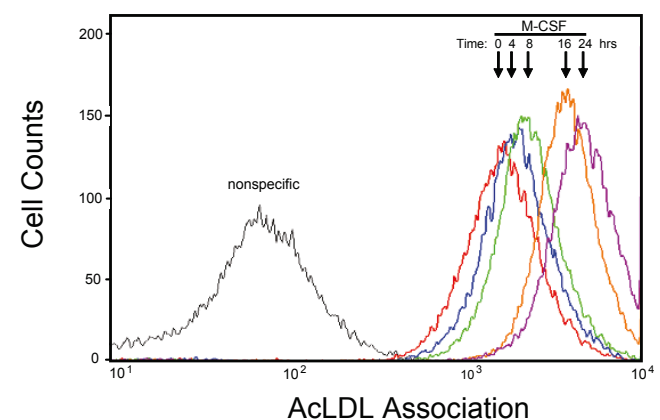

(fluorescence intensity)

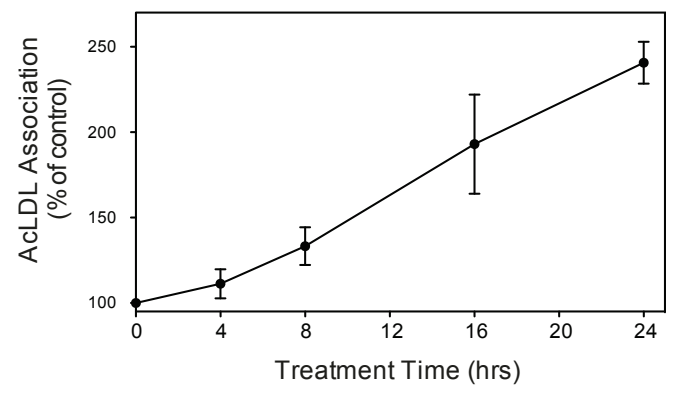

E

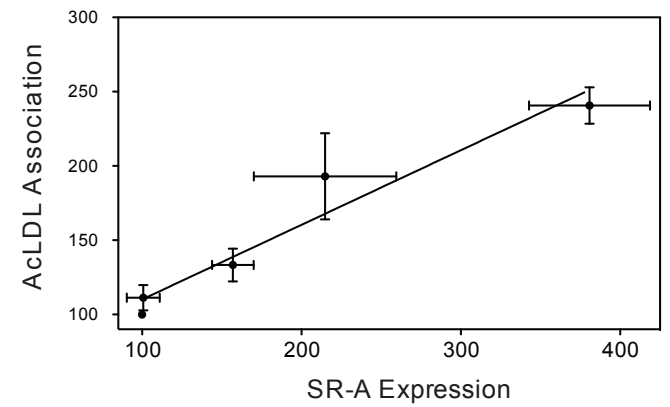

Figure 1 M-CSF induces SR-A expression and AcLDL association. (A) Cultured resident MPMs were incubated with the indicated concentrations of M-CSF for 24 hrs. Subsequently, SR-A and GAPDH proteins were detected in lysates prepared from treated cells by immunoblotting with specific antibodies. A representative immunoblot from a single experiment and the results (mean \pm SEM) from at least three separate experiments are shown. (B) Cultured resident MPMs were pretreated with actinomycin D $(5 \mu M)$ for 30 min, and then incubated with or without M-CSF $(25 \mathrm{ng} / \mathrm{ml})$ for the indicated times prior to assessing SR-A expression. A representative immunoblot from a single experiment and the results (mean \pm SEM) from at least three separate experiments are shown. (C) Alexa ${ }^{488}$-AcLDL association with macrophages isolated from $\mathrm{C} 57 \mathrm{BI} / 6$ or $\mathrm{NIH}-\mathrm{Sw}$ iss mice was quantified by flow cytometry as described in Material and Methods. Non-specific association was determined in the presence of fucoidan (Fuc, $75 \mu \mathrm{g} / \mathrm{ml}$ ), a blocking SR-A antibody (2F8, $10 \mu \mathrm{g} / \mathrm{ml}$ ), or by using SR-A-/- macrophages. Shown is the mean \pm SEM of three separate experiments. (D) SR-A-specific Alexa ${ }^{488}$-AcLDL association with macrophages incubated with M-CSF (25 $\mu \mathrm{g} /$ $\mathrm{ml}$ ) for the indicated times was quantified by flow cytometry as described in Material and Methods. The results of a representative experiment and the mean \pm SEM of at least three separate experiments are shown. (E) Relative changes in SR-A expression and function were plotted and the best fit line determined using a Deming linear regression model in GraphPad Prism. 


\section{Western blot analysis}

Equal amounts of cell lysate protein were resolved by $12 \%$ SDS-PAGE and transferred to polyvinylidene difluoride (PVDF) membrane (Millipore, Billerica, MA). Proteins were detected by immunoblotting with specific primary antibodies followed by incubation with speciesspecific HRP-conjugated secondary antibodies. Bands were visualized by chemiluminescence, images captured with a Kodak Image Station 4000 MM Pro, and band intensities quantified using Kodak 1D image analysis software.

\section{Flow Cytometry}

To assess SR-A-mediated lipoprotein uptake and surface accessible SR-A, cultured MPMs were preincubated for $2 \mathrm{hrs}$ in serum-free DMEM and then incubated for 2 hrs at $37^{\circ} \mathrm{C}$ with Alexa ${ }^{488}$-AcLDL $(2.5 \mu \mathrm{g} / \mathrm{ml})$. Nonspecific association of Alexa ${ }^{488}$-AcLDL with cells was defined in the presence of the SR-A ligand fucoidan $(75 \mu \mathrm{g} / \mathrm{ml})$ for 5 minutes prior to addition of lipoprotein. Nonspecific values were subtracted from total values to calculate SR-A-specific cell association. To quantify surface SR-A, MPMs were washed and incubated in DMEM/1\% FBS containing Alexa ${ }^{647}$-conjugated $2 \mathrm{~F} 8 \mathrm{mAb}$ for $30 \mathrm{~min}$ at $25^{\circ} \mathrm{C}$. Cells were then washed and suspended in PBS, and Alexa ${ }^{488}$-AcLDL and Alexa ${ }^{647}$-conjugated antibody association quantified by flow cytometry.

\section{Results and Discussion}

\section{$M-C S F$ induces SR-A expression and ACLDL association}

Macrophage differentiation and recruitment into inflammatory sites are associated with increased SR-A expression. SR-A expression is regulated by both transcriptional and post-transcriptional processing $[1,3,14,25,28-30]$. M-CSF is involved in both monocyte/ macrophage differentiation and recruitment during inflammation, and has previously been shown to enhance SR-A expression in elicited macrophages via increased transcription [14]. However, the intracellular signals that couple M-CSF to enhanced SR-A expression have not been defined.

To examine the signaling pathways that regulate SR-A expression, the effect of M-CSF on SR-A expression was examined in non-elicited, resident MPMs. Non-elicited, resident MPMs were used because of the potential for eliciting agents to alter macrophage phenotype and regulation by intracellular signals. Culturing isolated MPMs with $\mathrm{M}$-CSF resulted in the concentration-(Figure 1A) and time-(Figure 1B) dependent induction of SR-A protein expression. SR-A expression was increased by incubating macrophages with physiologically relevant (0.5-75 $\mathrm{ng} / \mathrm{ml})$ concentrations [31-33] of $\mathrm{M}-\mathrm{CSF}\left(\mathrm{EC}_{50} \approx 5 \mathrm{ng} /\right.$ $\mathrm{ml}$ ), and was maximally induced following a $24 \mathrm{hr}$ incubation with M-CSF (Figure 1B). No further increase in expression was observed with longer times of incubation with M-CSF (data not shown). Treating MPMs with actinomycin D $(5 \mu \mathrm{M})$, an inhibitor of gene transcription, prior to incubation with M-CSF abolished M-CSFmediated upregulation of SR-A expression indicating that M-CSF-stimulated SR-A expression in resident macrophages results from increased SR-A transcription. To confirm that increased SR-A expression is correlated with enhanced SR-A function, we examined the ability of M-CSF to stimulate fluorescently-labeled AcLDL (Alexa $^{488}$-AcLDL) association with MPMs. Results shown in Figure $1 \mathrm{C}$ show that a blocking SR-A monoclonal antibody (2F8) and an excess of SR-A competitor (fucoidan) reduced AcLDL association with macrophages isolated from $\mathrm{C} 57 \mathrm{Bl} / 6$ or $\mathrm{NIH}$-Swiss mice to a level similar to that obtained using macrophages isolated from SR-A-/- in a C57Bl/6 background. These results demonstrate the specificity of this asssay for assessing SR-A function. M-CSF treatment induced a time-dependent increase in AcLDL association with MPMs that was maximal (2.4-fold) at 24 hrs (Figure 1D), with no further increase at longer incubation times (data not shown). M-CSF stimulation of SR-A function was linearly correlated (Pearson $r=0.97 ; \mathrm{p}=0.007$ ) with the effect of M-CSF on SR-A expression (Figure 1E) indicating that in resident MPMs SR-A function is limited, at least in part, by the level of receptor expression. These results suggest that by increasing SR-A expression $M-$ CSF, produced for example by endothelial cells or lymphocytes in an atherosclerotic plaque or other inflammatory sites, can increase the uptake of modified lipoprotein and other scavenger receptor ligands.

\section{M-CSF-stimulates SR-A expression by upregulating SR-A mRNA and protein synthesis which requires p38 MAPK activation}

Many effects of M-CSF including macrophage migration, differentiation, survival, and cytokine production are mediated, in part, via activation of MAPKs, a family of kinases that include ERK1/2, JNK, and p38 [34-36]. Activation of MAPKs, in particular JNK and p38 MAPK, regulates the activity of several transcription factors including AP-1 [23]. The binding of AP-1 to an upstream enhancer element is sufficient to direct specific macrophage SR-A expression in inflammatory cells $[1,21,22]$. Therefore, we examined M-CSF-dependent MAPK activation and whether MAPK activation was required for $\mathrm{M}$-CSF-induced SR-A expression. For this, resident MPMs were treated with M-CSF and the activation of ERK, p38, and JNK assessed by immunoblotting with phospho-specific MAPK antibodies. As shown in Figure 2A, M-CSF induced the phosphorylation of both p38 and ERK1/2. In contrast, JNK phosphorylation was not detectable in either the presence or absence of 


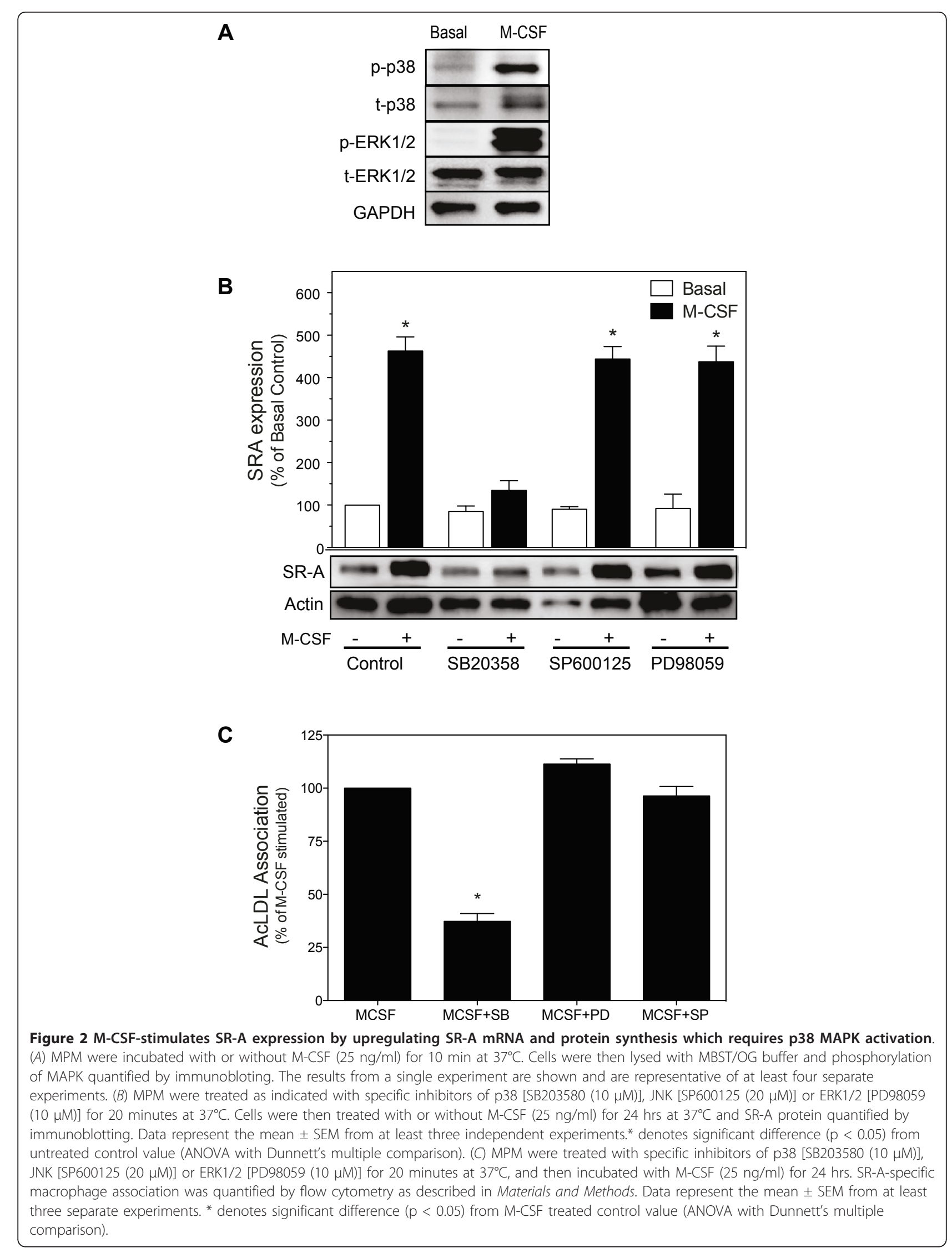


M-CSF (data not shown). To determine if activation of MAPK was specifically required for M-CSF-induced SRA expression and function, the ability of M-CSF to stimulate SR-A expression and AcLDL association was assessed in MPMs pretreated with specific inhibitors of p38 MAPK (SB203580), JNK (SP600125), and MEK1 (PD98059), which inhibits ERK1/2 activation. Inhibiting JNK or ERK1/2 activation had no effect on either M-CSF-induced SR-A expression (Figure 2B) or M-CSFinduced uptake of modified lipoprotein (Figure 2C). In contrast, pretreating macrophages with SB203580 inhibited both M-CSF-induced SR-A expression and modified lipoprotein uptake (Figure 2C). Together, these data define a specific requirement for activation of p38 MAPK, but not ERK1/2 and JNK, in M-CSF-induced SR-A expression and function.
M-CSF stimulates SR-A expression and ACLDL association in reversible manner

Increased SR-A expression and function following MCSF treatment suggests that regulating SR-A expression in resident macrophages is an adaptive response to changes in the local inflammatory environment. Inflammation is a dynamic process in which the production of cytokines such as M-CSF changes as inflammation resolves over time. To test whether the enhanced SR-A expression and function induced by M-CSF is reversible, we examined SR-A protein and AcLDL uptake following removal of M-CSF using the incubation scheme depicted in Figure 3A. The increase in SR-A expression, as quantified by western blotting (Figure $3 \mathrm{~B}$ ) or flow cytometry (Figure 3Ctop), and function (Figure 3Cbottom) observed following M-CSF treatment returned to
A
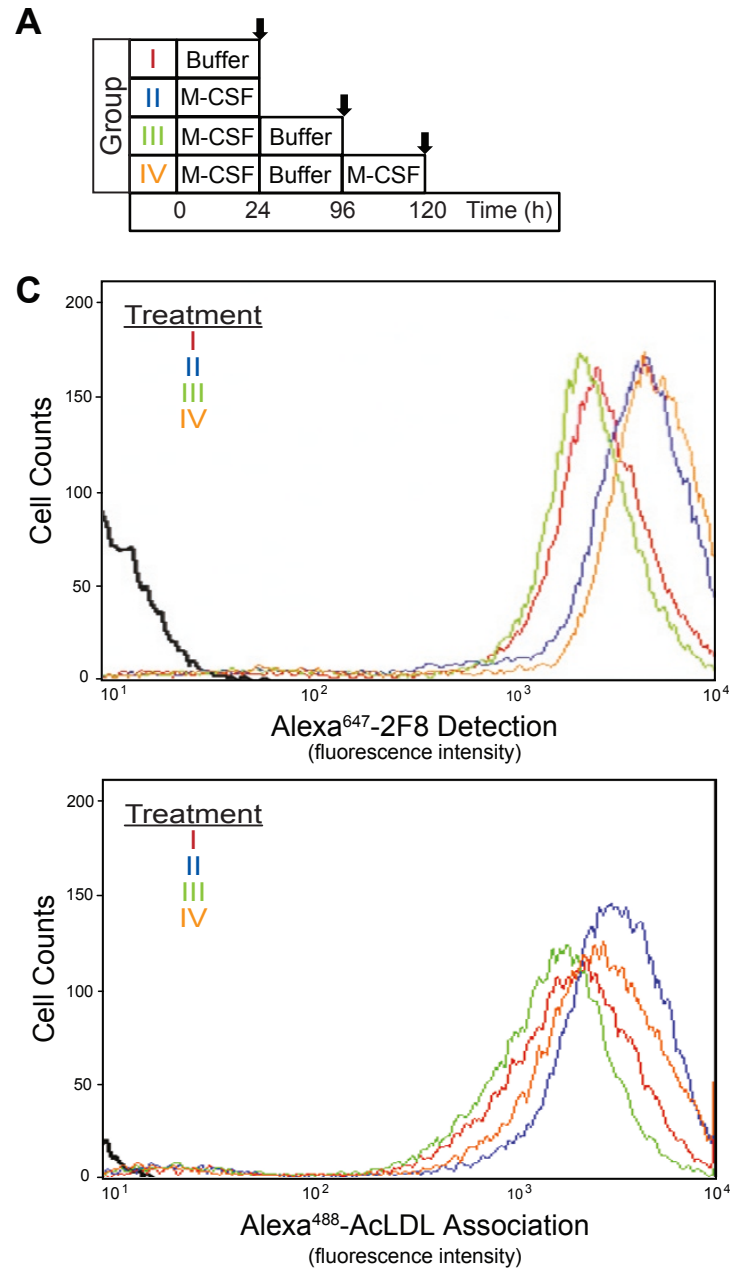

B

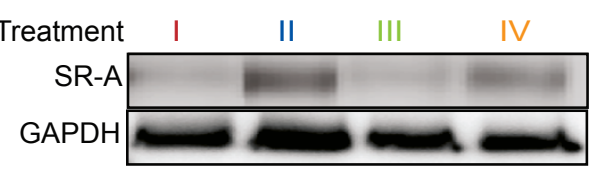

D

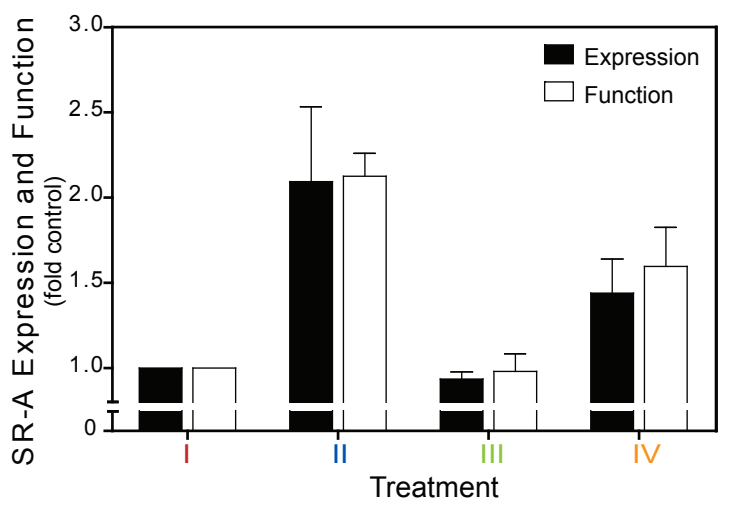

Figure 3 M-CSF reversibly stimulates SR-A expression and AcLDL association. (A) Incubation scheme: Cultured resident MPM were incubated (I) without M-CSF; (II) with M-CSF $(25 \mathrm{ng} / \mathrm{ml})$ for $24 \mathrm{hrs}$; (III) with M-CSF (25 ng/ml) for 24 hrs and then in absence of M-CSF for additional $72 \mathrm{hrs}$; or (IV) with M-CSF (25 ng/ml) for $24 \mathrm{hrs}$, then in absence of M-CSF for additional 72 hrs, and incubated again with M-CSF (25 $\mathrm{ng} / \mathrm{ml}$ ) for $24 \mathrm{hrs}$. SR-A expression and function were assessed at the end of incubation (arrows). (B) Following incubations, cell lysates were prepared and SR-A protein was quantified by immunoblotting. (C) Following incubations, surface SR-A (top) and SR-A-mediated uptake (bottom) were quantified by flow cytometry using Alexa ${ }^{647}$-conjugated $2 \mathrm{~F} 8 \mathrm{mAb}$ and Alexa ${ }^{488}$-AcLDL as described in Materials and Methods. The results of representative experiments are shown. (D) The mean \pm SEM of at least three separate flow cytometry experiments are shown. 


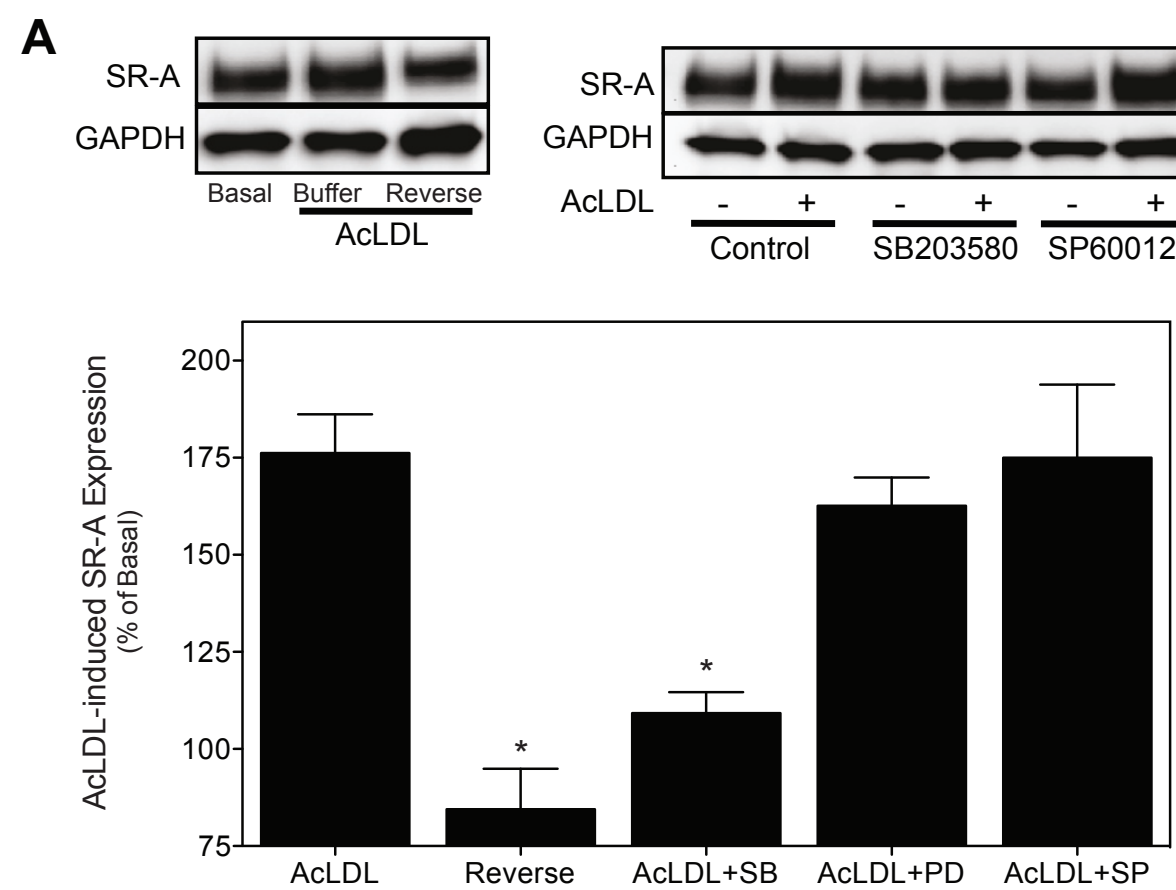

B
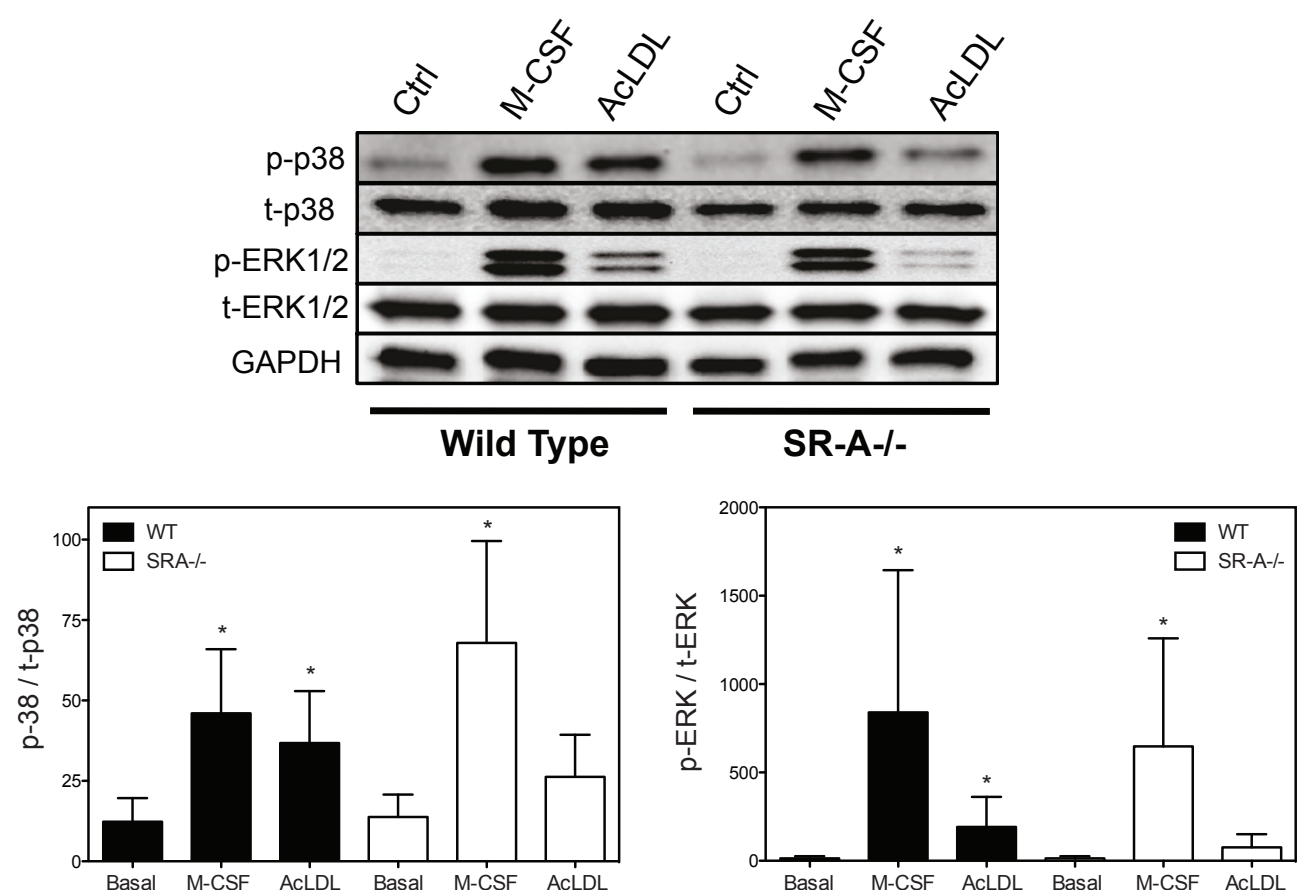

Figure 4 AcLDL reversibly stimulates SR-A expression via activation of p38 MAPK. (A) Cultured resident MPM were pretreated, as

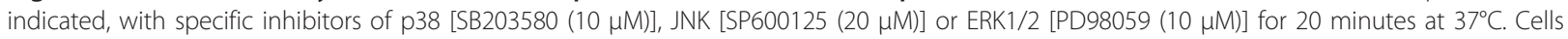
were then treated with or without AcLDL $(50 \mathrm{\mu g} / \mathrm{ml})$ for $24 \mathrm{hrs}$ at $37^{\circ} \mathrm{C}$, and as indicated incubated without AcLDL for additional $72 \mathrm{hrs}$ (Reverse). Cell lysates were prepared and SR-A protein expression quantified by immunoblotting. A representative immunoblot from a single experiment and the results (mean \pm SEM) from at least three separate experiments are shown. ${ }^{*}$ denotes significant difference $(p<0.05)$ from AcLDL treated control value (ANOVA with Dunnett's multiple comparison). (B) To determine whether AcLDL induces MAPK activation in SR-A dependent manner, MPM from wild type and SR-A-/- mice were cultured for $48 \mathrm{hrs}$ and then incubated without or with M-CSF (25 ng/ml) or AcLDL $(50 \mu \mathrm{g} / \mathrm{ml})$ for $10 \mathrm{~min}$. Cells lysates were prepared and phosphorylation of individual MAPKs detected by immunoblotting. A representative immunoblot from a single experiment and the results (mean $\pm \mathrm{SEM}$ ) from at least three separate experiments are shown. * denotes significant difference $(p<0.05)$ from untreated wild-type value (ANOVA with Dunnett's multiple comparison). 
the pretreated levels $72 \mathrm{hr}$ after M-CSF removal (t $1 / 2 \approx$ $24 \mathrm{hr}$ ). To determine if SR-A expression was still responsive to M-CSF, previously treated MPMs were restimulated with M-CSF for another $30 \mathrm{hrs}$. Similar to naïve MPMs, SR-A expression and function were increased by the restimulation with M-CSF. As summarized in Figure 3D, M-CSF-induced proportional changes in SR-A expression and function in both naïve and previously treated MPMs. Together, these data demonstrate that in resident macrophages SR-A expression and function is dynamically regulated by M-CSF.

\section{AcLDL stimulates SR-A expression in reversible manner via activation of p38 MAPK}

In addition to cytokines, inflammatory settings are characterized by accumulation of SR-A ligands including oxidized lipoproteins (e.g., modified LDL), necrotic cell debris, and modified ECM. Because many receptors are down-regulated by chronic exposure to ligand, we tested whether SR-A expression was decreased by ligand. In contrast to our hypothesis, incubating macrophages with an SR-A selective ligand (AcLDL; $50 \mu \mathrm{g} / \mathrm{ml}$ ) for $24 \mathrm{hr}$ increased SR-A protein expression (Figure 4A). As demonstrated for M-CSF, enhanced SR-A expression returned to the pretreated levels $72 \mathrm{hr}$ after AcLDL was removed, and pre-treating MPMs with a specific p38 MAPK inhibitor (SB203580) blocked AcLDL-induced SR-A expression. In contrast, inhibitors of ERK1/2 and JNK did not affect the ability of AcLDL to enhance SRA expression. To confirm that incubating resident MPMs with AcLDL induced SR-A-dependent MAPK activation, the ability of AcLDL to activate MAPK in wild-type and SR-A deficient resident MPMs was examined. As shown in Figure 4B, treating macrophages with AcLDL $(50 \mu \mathrm{g} / \mathrm{ml}, 10 \mathrm{~min})$ induced phosphorylation of p38 MAPK and ERK1/2 in wild-type but not in SR-A deficient macrophages. In contrast, p38 MAPK and ERK1/2 phosphorylation were similarly increased in both wild type and SR-A deficient MPMs treated with M-CSF. JNK phosphorylation was not detected in any treatment group (data not shown). Together, these data indicate that ligand binding to SR-A is positively coupled to SR-A expression via specifically activating p38 MAPK.

Regulating SR-A expression in vivo may be relevant to many inflammatory disorders. For example, M-CSF plays important roles in inflammation and immunity. M-CSF increases anti-tumor and anti-infective functions of macrophages, whereas M-CSF deficiency decreases atherosclerosis and impairs osteoclast development $[11,37]$. The extent to which these effects depend on altered SR-A expression remains to be defined. However, the possibility that regulating SR-A expression modulates inflammatory responses is suggested by the many studies showing that decreased SR-A expression is associated with reduced atherosclerosis, increased susceptibility to infection, disease progression in prostate cancer, and dysregulation of bone development [8,9,38-40]. Like SR-A, activation of p38 MAPK is important for many inflammatory processes including the production of TNF $\alpha$, IL- $1 \beta$, and other cytokines $[41,42]$. In addition, inhibiting p38 MAPK has shown potential benefit in the treatment of inflammatory disease $[43,44]$. Our findings suggest that the effects of MCSF and p38 MAPK on immune and inflammatory processes may be mediated, in part, by modulating SR-A expression.

\section{Conclusions}

Our results indicate that resident tissue macrophages adapt to changes in their local environment by modulating SR-A expression and function. Such modulation may involve the local secretion of M-CSF, which increases SR-A expression via activating p38 MAPK. Unlike many receptor systems which are down-regulated by ligand, ligand binding to SR-A up-regulates SR-A expression by activating p38 MAPK. Increased SR-A expression might modulate inflammation by enhancing macrophage uptake and clearance of modified protein/ lipid, bacteria, and cell debris. In addition, SR-Amediated p38 MAPK activation may regulate the production of inflammatory cytokines, growth factors, and proteolytic enzymes, and therefore modulate the progression of many inflammatory disorders [18-20]. This may be of particular importance in settings where SR-A ligands accumulate such as atherosclerosis, diabetes, and Alzheimer's disease.

\section{Acknowledgements}

This work was supported by a Cardiovascular Training grant (T32HL072743; LK) and grants from the NIH (RO1HL88588 and RO1HL075241) and an Established Investigator Award from the American Heart Association (SRP).

\section{Author details}

${ }^{1}$ Department of Pathology, University of Arkansas for Medical Sciences, Little Rock, Arkansas, 72205 USA. ${ }^{2}$ Department of Molecular and Biomedical Pharmacology, University of Kentucky, Lexington, Kentucky, 40536 USA. ${ }^{3}$ Harold C. Simmons Comprehensive Cancer Center, University of Texas Southwestern Medical Center, Dallas, Texas, 75390 USA.

\section{Authors' contributions}

DN contributed to performing and analyzing experiments, and in preparing manuscript. LC and LD contributed to performing and analyzing experiments. SRP contributed to experimental design, interpretation of results, and manuscript preparation. All authors read and approved the final manuscript

\section{Competing interests}

The authors declare that they have no competing interests.

Received: 20 January 2011 Accepted: 7 July 2011 Published: 7 July 2011 


\section{References}

1. Wu H, Moulton K, Horvai A, Parik S, Glass CK: Combinatorial interactions between AP-1 and ets domain proteins contribute to the developmental regulation of the macrophage scavenger receptor gene. Mol Cell Biol 1994, 14(3):2129-2139.

2. Geng $Y$, Kodama T, Hansson GK: Differential expression of scavenger receptor isoforms during monocyte-macrophage differentiation and foam cell formation. Arterioscler Thromb 1994, 14(5):798-806.

3. Fukuhara-Takaki K, Sakai M, Sakamoto Y-i, Takeya M, Horiuchi S: Expression of class A scavenger receptor is enhanced by high glucose in vitro and under diabetic conditions in vivo; one mechanism for an increased rate of atherosclerosis in diabetes. J Biol Chem 2004, M408715200.

4. Naito M, Suzuki H, Mori T, Matsumoto A, Kodama T, Takahashi K: Coexpression of type I and type II human macrophage scavenger receptors in macrophages of various organs and foam cells in atherosclerotic lesions. Am J Pathol 1992, 141(3):591-599.

5. Gough PJ, Greaves DR, Suzuki H, Hakkinen T, Hiltunen MO, Turunen M, Herttuala SY, Kodama T, Gordon S: Analysis of macrophage scavenger receptor (SR-A) expression in human aortic atherosclerotic lesions. Arterioscler Thromb Vasc Biol 1999, 19(3):461-471.

6. Husemann J, Loike JD, Anankov R, Febbraio M, Silverstein SC: Scavenger receptors in neurobiology and neuropathology: their role on microglia and other cells of the nervous system. Glia 2002, 40(2):195-205.

7. Haworth R, Platt N, Keshav S, Hughes D, Darley E, Suzuki H, Kurihara Y Kodama T, Gordon S: The macrophage scavenger receptor type $A$ is expressed by activated macrophages and protects the host against lethal endotoxic shock. Journal of Experimental Medicine 1997, 186(9):1431-1439.

8. Suzuki H, Kurihara Y, Takeya M, Kamada N, Kataoka M, Jishage K, Ueda O, Sakaguchi H, Higashi T, Suzuki T, Takashima Y, Kawabe Y, Cynshi O, Wada Y, Honda M, Kurihara H, Aburatani H, Doi T, Matsumoto A, Azuma S, Noda T, Toyoda Y, Itakura H, Yazaki Y, Horiuchi S, Takahashi K, Kruijt JK, van Berkel TJC, Steinbrecher UP, Ishibashi S, Maeda N, Gordon S, Kodama T: A role for macrophage scavenger receptors in atherosclerosis and susceptibility to infection. Nature 1997, 386(6622):292-296.

9. Yang G, Addai J, Tian WH, Frolov A, Wheeler TM, Thompson TC: Reduced infiltration of class $A$ scavenger receptor positive antigen-presenting cells is associated with prostate cancer progression. Cancer Res 2004, 64(6):2076-2082

10. Pixley FJ, Stanley ER: CSF-1 regulation of the wandering macrophage: complexity in action. Trends in Cell Biology 2004, 14(11):628-638.

11. Stanley ER, Berg KL, Einstein DB, Lee PS, Pixley FJ, Wang Y, Yeung YG: Biology and action of colony-stimulating factor-1. Mol Reprod Dev 1997, 46(1):4-10.

12. Chitu V, Stanley ER: Colony-stimulating factor-1 in immunity and inflammation. Curr Opin Immunol 2006, 18(1):39-48.

13. Whitman SC, Daugherty A, Post SR: Macrophage colony-stimulating factor rapidly enhances beta-migrating very low density lipoprotein metabolism in macrophages through activation of a $\mathrm{Gi} /$ o protein signaling pathway. J Biol Chem 2000, 275(46):35807-35813.

14. de Villiers WJ, Fraser IP, Hughes DA, Doyle AG, Gordon S: Macrophagecolony-stimulating factor selectively enhances macrophage scavenger receptor expression and function. J Exp Med 1994, 180(2):705-709.

15. Goldstein JL, Ho YK, Basu SK, Brown MS: Binding site on macrophages that mediates uptake and degradation of acetylated low density lipoprotein, producing massive cholesterol deposition. Proc Natl Acad Sci USA 1979, 76(1):333-337.

16. Platt N, Suzuki H, Kurihara Y, Kodama T, Gordon S: Role for the class A macrophage scavenger receptor in the phagocytosis of apoptotic thymocytes in vitro. Proc Natl Acad Sci USA 1996, 93(22):12456-12460.

17. Fraser I, Hughes D, Gordon S: Divalent cation-independent macrophage adhesion inhibited by monoclonal antibody to murine scavenger receptor. Nature 1993, 364(6435):343-346

18. Hsu HY, Hajjar DP, Khan KM, Falcone DJ: Ligand binding to macrophage scavenger receptor-A induces urokinase-type plasminogen activator expression by a protein kinase-dependent signaling pathway. J Biol Chem 1998, 273(2):1240-1246.

19. Hsu H-Y, Chiu S-L, Wen M-H, Chen K-Y, Hua K-F: Ligands of Macrophage Scavenger Receptor Induce Cytokine Expression via Differential Modulation of Protein Kinase Signaling Pathways. J Biol Chem 2001, 276(31):28719-28730.
20. Pollaud-Cherion C, Vandaele J, Quartulli F, Seguelas MH, Decerprit J, Pipy B: Involvement of calcium and arachidonate metabolism in acetylated-lowdensity-lipoprotein-stimulated tumor-necrosis-factor-alpha production by rat peritoneal macrophages. Eur J Biochem 1998, 253(1):345-353.

21. Moulton KS, Wu H, Barnett J, Parthasarathy S, Glass CK: Regulated expression of the human acetylated low density lipoprotein receptor gene and isolation of promoter sequences. Proc Natl Acad Sci USA 1992, 89(17):8102-8106.

22. Moulton KS, Semple K, Wu H, Glass CK: Cell-specific expression of the macrophage scavenger receptor gene is dependent on PU.1 and a composite AP-1/ets motif. Mol Cell Biol 1994, 14(7):4408-4418.

23. Guha M, Mackman N: LPS induction of gene expression in human monocytes. Cellular Signalling 2001, 13(2):85-94.

24. Xu W, Wang L, Wang H, Wang Y, Liang Y, Zhao T, Wu Y: TLR2 and TLR4 agonists synergistically up-regulate SR-A in RAW264.7 through p38. Molecular Immunology 2007, 44(9):2315-2323.

25. Ricci R, Sumara G, Sumara I, Rozenberg I, Kurrer M, Akhmedov A, Hersberger M, Eriksson U, Eberli FR, Becher B, Boren J, Chen M, Cybulsky MI Moore KJ, Freeman MW, Wagner EF, Matter CM, Luscher TF: Requirement of JNK2 for Scavenger Receptor A-Mediated Foam Cell Formation in Atherogenesis. Science 2004, 306(5701):1558-1561

26. Chen Y, Bradley SF: Aging and eliciting agents: effect on murine peritoneal macrophage monokine bioactivity. Exp Gerontol 1993, 28(2):145-159

27. Shaw DR, Griffin FM Jr: Thioglycollate-elicited mouse peritoneal macrophages are less efficient than resident macrophages in antibodydependent cell-mediated cytolysis. J Immunol 1982, 128(1):433-440.

28. Whitman SC, Daugherty A, Post SR: Regulation of acetylated low density lipoprotein uptake in macrophages by pertussis toxin-sensitive $G$ proteins. J Lipid Res 2000, 41(5):807-813.

29. Mietus-Snyder M, Glass CK, Pitas RE: Transcriptional Activation of Scavenger Receptor Expression in Human Smooth Muscle Cells Requires AP-1/C-Jun and C/EBPß: Both AP-1 Binding and JNK Activation Are Induced by Phorbol Esters and Oxidative Stress. Arterioscler Thromb Vasc Biol 1998, 18(9):1440-1449.

30. Fong $L G$, Le $D$ : The processing of ligands by the class $A$ scavenger receptor is dependent on signal information located in the cytoplasmic domain. J Biol Chem 1999, 274(51):36808-36816.

31. Cheers C, Stanley ER: Macrophage production during murine listeriosis: colony-stimulating factor 1 (CSF-1) and CSF-1-binding cells in genetically resistant and susceptible mice. Infection and immunity 1988, 56(11):2972-2978.

32. Praloran V, Raventos-Suarez C, Bartocci A, Lucas J, Stanley ER, Gibbons JJ Jr: Alterations in the expression of colony-stimulating factor- 1 and its receptor during an acute graft-vs-host reaction in mice. Journal of immunology 1990, 145(10):3256-3261.

33. Roth $\mathrm{P}$, Stanley ER: Colony stimulating factor- 1 expression is developmentally regulated in the mouse. Journal of leukocyte biology 1996, 59(6):817-823.

34. Jaworowski A, Wilson NJ, Christy E, Byrne R, Hamilton JA: Roles of the Mitogen-activated Protein Kinase Family in Macrophage Responses to Colony Stimulating Factor-1 Addition and Withdrawal. J Biol Chem 1999, 274(21):15127-15133

35. Valledor AF, Comalada M, Xaus J, Celada A: The differential time-course of extracellular-regulated kinase activity correlates with the macrophage response toward proliferation or activation. J Biol Chem 2000, 275(10):7403-7409.

36. Wang Y, Zeigler MM, Lam GK, Hunter MG, Eubank TD, Khramtsov W, Tridandapani S, Sen CK, Marsh CB: The Role of the NADPH Oxidase Complex, p38 MAPK, and Akt in Regulating Human Monocyte/ Macrophage Survival. Am J Respir Cell Mol Biol 2007, 36(1):68-77.

37. Rajavashisth T, Qiao J-H, Tripathi S, Tripathi J, Mishra N, Hua M, Wang X-P, Loussararian A, Clinton S, Libby P, Lusis A: Heterozygous Osteopetrotic (op) Mutation Reduces Atherosclerosis in LDL Receptor-deficient Mice. J Clin Invest 1998, 101(12):2702-2710.

38. Lin YL, de Villiers WJ, Garvy BA, Post SR, Nagy TR, Safadi FF, Faugere MC, Wang G, Malluche HH, Williams JP: The effect of class A scavenger receptor (SR-A) deficiency in bone. J Biol Chem 2006.

39. Babaev VR, Gleaves LA, Carter KJ, Suzuki H, Kodama T, Fazio S, Linton MF: Reduced Atherosclerotic Lesions in Mice Deficient for Total or 
Macrophage-Specific Expression of Scavenger Receptor-A. Arterioscler Thromb Vasc Biol 2000, 20(12):2593.

40. Whitman SC, Rateri DL, Szilvassy SJ, Cornicelli JA, Daugherty A: Macrophage specific expression of class A scavenger receptors in LDL receptor-/mice decreases atherosclerosis and changes spleen morphology. J Lipid Res 2002, 43(8):1201.

41. Lee JC, Laydon JT, McDonnell PC, Gallagher TF, Kumar S, Green D, McNulty D, Blumenthal MJ, Keys JR, Land vatter SW, Strickler JE, McLaughlin MM, Siemens IR, Fisher SM, Livi GP, White JR, Adams JL, Young PR: A protein kinase involved in the regulation of inflammatory cytokine biosynthesis. Nature 1994, 372(6508):739-746.

42. Westra J, Limburg PC, de Boer P, van Rijswijk MH: Effects of RWJ 67657, a p38 mitogen activated protein kinase (MAPK) inhibitor, on the production of inflammatory mediators by rheumatoid synovial fibroblasts. Ann Rheum Dis 2004, 63(11):1453-1459.

43. Westra J, Limburg PC: p38 mitogen-activated protein kinase (MAPK) in rheumatoid arthritis. Mini Rev Med Chem 2006, 6(8):867-874.

44. Lee JC, Kumar S, Griswold DE, Underwood DC, Votta BJ, Adams JL: Inhibition of p38 MAP kinase as a therapeutic strategy. Immunopharmacology 2000, 47(2-3):185-201.

doi:10.1186/1471-2172-12-37

Cite this article as: Nikolic et al.: SR-A ligand and M-CSF dynamically regulate SR-A expression and function in primary macrophages via p38 MAPK activation. BMC Immunology 2011 12:37.

\section{Submit your next manuscript to BioMed Central and take full advantage of:}

- Convenient online submission

- Thorough peer review

- No space constraints or color figure charges

- Immediate publication on acceptance

- Inclusion in PubMed, CAS, Scopus and Google Scholar

- Research which is freely available for redistribution

Submit your manuscript at www.biomedcentral.com/submit 